\title{
FRIENDSHIP AMONG ADULT FEMALE BLUE MONKEYS (CERCOPITHECUS MITIS)
}

\author{
by
}

\begin{abstract}
MARINA CORDS ${ }^{1,2)}$
(Department of Ecology, Evolution and Environmental Biology, Columbia University, New York, NY 10027, USA)
\end{abstract}

(Acc. 30-XI-2001)

\begin{abstract}
Summary
A study group of blue monkeys in the Kakamega Forest, Kenya, provides data on friendly relationships between adult females. Females are invariably antagonistic toward members of other groups, and collaborate with their own groupmates in defending territorial boundaries. Females are primarily responsible for these aggressive intergroup encounters, which occur every other day on average. Encounters are often immediately followed by intense grooming among adult females, which gives the impression of reinforcing the collaborative team. In some lower-density populations, intergroup aggression is rare; in these populations, and at Kakamega as well, female groupmates may provide other or additional services, such as protection against predators or aggressive males. Friendships among females of a single group are differentiated. Individuals interact with certain grooming and proximity partners much more than others. Despite low rates of agonism, blue monkey females also show stable
\end{abstract}

1) Author's e-mail address: mc51@ columbia.edu

2) I am grateful to the Government of Kenya, Office of the President and Ministry of Education, Science and Technology for permission to conduct research in the Kakamega Forest, to the University of Nairobi's Zoology Department and the Institute for Primate Research (National Museums of Kenya) for local sponsorship, and to the local officers of the Forestry Department and Kenya Wildlife Service for cooperation at the field site. For assistance with data gathering, I thank especially Karen Pazol, Simon Mbugua, Steffen Foerster, Jasper Kirika, and Joel Glick, as well as those Kenyan and American students who assisted with observations for shorter periods. For enabling my long hours in the field, I thank Caroline Okoyo. Jade Gibson and Katie Ross helped enormously with computer entry of field notes. Joan Silk and two anonymous reviewers made helpful suggestions during preparation of the manuscript. My study of blue monkeys at Kakamega has been supported by Columbia University, and by the Wenner Gren Foundation, L.S.B. Leakey Foundation, and National Science Foundation (SBR 95-23623, BCS 98-08273). 
if shallow dominance relationships, and linear hierarchies. Rank is not correlated with diet, feeding behavior or reproductive rate. Coalition formation is rare, and these females do not groom up the hierarchy. Grooming may simply be traded for itself, leading to highly symmetrical grooming bouts. Blue monkeys have been misclassified in theoretical papers on socioecology. Their behavior seems not to fit these models well, because certain features of their social system, related to within-group contest competition, do not co-occur as expected. Their hierarchical dominance relationships are also surprising, because rank seems to be uncorrelated with fitness-related variables. Finally, the rarity of affiliative behavior exhibited by these monkeys suggests that new ways of measuring friendships may be appropriate. The possible importance of, and reasons for, rare within-group coalitions are discussed.

\section{Introduction}

In gregarious species, one can differentiate the structure of social relationships on two levels. First, an individual interacts with its groupmates in ways that differ from its interactions with non-groupmates, so from a population perspective, almost everyone in its group might be considered a 'friend'. Second, relationships with all groupmates are usually not equivalent, so one might also use the term 'friend' to differentiate those dyads within a single group in which certain types of behavior (particularly affiliative) are extraordinarily common. In these contexts, I am using the term 'friendship' rather loosely to differentiate social relationships along a dimension of the amount of friendly interaction. While a case can certainly be made for a more restrictive connotation (Silk, this volume), it is also true that humans sometimes use this term broadly, as I do here.

A series of influential papers on the ecological basis of variation in female relationships among primates has identified between-group contest competition as having an important influence on within-group social relationships (Wrangham, 1980; van Schaik, 1989; Sterck et al., 1997). These models share the basic idea that the need for cooperative defense of resources against other groups will cause the members of one group to have mutual relationships that enable such cooperation: kinship (to counteract any collective action problem), affiliative bonding (but see Cheney, 1992), and a lack of extreme hostility are presumed to be necessary prerequisites. Even when contest competition occurs within a single group, leading to regular dominance relationships and coalition formation against groupmates, high-ranking individuals are expected to be more tolerant than they might be given their relative power because they depend on lower-ranking groupmates (who may 
have the option to leave) as partners when confronting neighboring groups (van Schaik, 1989; Sterck et al., 1997). In agreement with these predictions, Isbell \& van Vuren (1996) documented that female dispersal occurs less frequently in Old World anthropoid populations where groups show mutual antagonism than in populations where such antagonism is rare or absent. On the other hand, Matsumura (1999) has disputed whether more 'egalitarian' social systems are associated with stronger (at least more frequent) betweengroup competition, at least in macaques.

Blue monkeys (Cercopithecus mitis), and indeed forest-dwelling guenons generally, have figured little in the development of the theory outlined above (e.g. Wrangham, 1980; van Schaik, 1989; but see Hemelrijk \& Luteijn, 1998; Isbell, 1991), because little relevant information has been available for these species. Along with other forest guenons, blue monkeys have generally been characterized as showing strong between-group competition in the form of territoriality, but egalitarian and undifferentiated relationships with their groupmates. In this paper, I evaluate these characterizations by using all available data to examine friendship among adult female blue monkeys, both from a population perspective and from a within-group perspective. I begin with a description of female friendships based largely on my own study of a population of $C$. mitis stuhlmanni inhabiting the Kakamega Forest, western Kenya, which has been under intermittent observation since 1979. Where possible, I compare the findings from this population with those from other populations in which social behavior has been explicitly studied, mainly in Uganda (Kibale Forest, also C. mitis stuhlmanni) and South Africa (Cape Vidal, C. mitis erythrarchus). The results of these studies are not wholly consistent with theory, and raise additional questions about how we measure and interpret behavior that reveals the nature of within-group friendly relationships.

\section{Background information on study site, subjects, and methods}

The Kakamega Forest in western Kenya is a rain forest fragment whose main block is approximately $86 \mathrm{~km}^{2}$ (Brooks et al., 1999), located at about $1650 \mathrm{~m}$, and receiving an average annual rainfall of over $2000 \mathrm{~mm}$. Two rainy and two dry seasons per year can usually be distinguished, but there is much interannual variation. Cords (1987a) provides a more thorough description of the study site.

Blue monkeys at Kakamega occur at a density of approximately 170-220 individuals $/ \mathrm{km}^{2}$ (Cords, 1987a; Fashing \& Cords, 2000), with the higher figures in this range more representative of the periods in the last 8 years when female social behavior was most intensively 
sampled (see below). This is a high population density for the species, but similar to that at Cape Vidal, South Africa (202 individualsha, Lawes \& Henzi, 1995) which provides comparable data. Another well-studied population, in the Kibale Forest, Uganda, occurs at lower population densities $\left(223 \mathrm{~kg} / \mathrm{km}^{2}\right.$ at the Kanyawara study site, $<26 \mathrm{~kg} / \mathrm{km}^{2}$ at the Ngogo study site, vs $624-645 \mathrm{~kg} / \mathrm{km}^{2}$ for Kakamega; Butynski, 1990; Fashing \& Cords, 2000).

I have studied the blue monkeys of Kakamega over a period of 21 years (beginning in 1979). The results presented here include reports from prior studies (especially Cords, 2000), further developments of data on which these earlier reports were based, and some new results. As the focus of this paper is a synthesis of all these findings, and because repetition of the various data gathering methods would take up much space, I present only a brief overview of the methods underlying the findings which are discussed here, with references to more complete descriptions of the methods and findings where appropriate. Four study groups contributed to the results presented: Tw, with about 35-50 members studied over a 21 year period, $\mathrm{G}$ with about 35-40 individuals studied over a 5 year period, and the products of $\mathrm{G}$ group's fission, Gn and Gs, with with 21-27 and 29-39 individuals respectively, studied over a 2 year period.

Relations between blue monkey groups have not been extensively documented for this population, although a brief description was made by Cords (1987a) based on approximately 1750 hours of contact with one focal group between 1979 and 1981. The qualitative descriptions of intergroup relations presented in this paper are based on thousands of additional hours of observation of all four study groups between 1982 and 2001. Quantitative estimates of the frequency of aggressive intergroup encounters derive from a period between July 1998 and February 2001, in which regular (and for most of the time, daily) observations were made on 2-3 study groups. Rates are expressed as encounters per day (and days without observations were excluded from the calculation). Observation days lasted 10-12 hours. Intergroup encounters that did not include aggression were easily missed, and not quantified.

Within-group social relations in this population have been described by Rowell et al. (1991) and by Cords (2000); the latter paper is the source for many of the results discussed here. These earlier analyses of female relationships in one social group (Tw) were based both on ad libitum observations of agonism (for determining dominance relationships), and 16 hours of focal sampling on 13 adult females over two consecutive years, plus 5 and 11 hours for two additional females who were sampled in just one of the two years. While not all females were parous at the time of sampling, they were all of adult body size, and behaved in ways that resembled parous adult females rather than juveniles: specifically, they never played, and groomed with a range of adult partners. With a few exceptions, kinship relations among these adult females were not known. Focal sample data were used to study behavioral rates, and the spectrum of social partners of each female (Cords, 2000). Focal samples involved a continuous record of activity of each subject. Focal samples were scheduled to control for temporal variation in activity and variation in habitat use.

\section{Friendships: group-mates $v s$ others}

Blue monkeys are often (but not always) reported as being territorial, such that members of one group are aggressive towards those of another group when they meet at range boundaries, and/or home ranges overlap little 
(Rudran, 1978; Butynski, 1990; Lawes \& Henzi, 1995). The blue monkeys at Kakamega show considerable range overlap (as much as half of the group's home range may be shared with other groups), and neighboring groups may be in close proximity without showing any signs of aggression. Longterm study of this population, however, makes it clear that the groups (and especially their adult female members) are antagonistic toward one another, and do defend territorial boundaries which are remarkably consistent over periods of years and even decades. The position of the boundary can be pinpointed to individual trees or to general areas on the home range's periphery where aggressive intergroup encounters most often occur. When two neighboring groups show peaceful proximity, it is nearly always because each remains on its side of this territorial boundary (see also Rudran, 1978).

Incursions into a neighboring group's home range are not infrequent. Dramatic incursions, when the trespassing group moves $100 \mathrm{~m}$ or more across the territorial boundary, appear to be motivated by the availability of an unusually attractive food source (e.g. a large fig tree). Minor incursions are also associated with feeding, in that blue monkeys almost always feed intermittently while moving; minor incursions, however, often do not involve large, rich sources of food. Incursions are most likely, and most extensive, when the neighboring group is far away, and probably unaware of the trespassing. Many times I have witnessed how one (usually peripheral) member of the neighboring group discovers the interlopers, chirps loudly, resulting in rapid recruitment of her groupmates who jointly chase the trespassing group back to the far side of the territorial boundary. In fact, the trespassing group often responds to the strengthening chorus of loud chirps by retreating to its own territory before any direct confrontations have a chance to occur, and even when the number of trespassers exceeds the number of residents who are mobilized as challengers. One has the impression that the monkeys know where they, and their neighbors, belong, but it is the threat of aggression that keeps each group in its place.

Adult females from neighboring groups at Kakamega never show overtly friendly behavior, such as sitting in close proximity or grooming. Rather, direct behavioral exchanges are always antagonistic, involving threats (aggressive growling, stares, and lunges), chases and sometimes grappling combat. Further, most intergroup fighting is carried out by females, especially adults and large juveniles. Smaller juveniles (of either sex) and adult males are seldom involved. Occasionally, an adult male may join in with his females 
during peaks of escalated aggression, but his participation is typically brief. However, adult males often punctuate the females' aggressive interactions with loud calls (booms and pyows). Juvenile males show behavior very different from that of females: these young males may play with peers from the neighboring group, even as the females are interacting antagonistically nearby. This contrast highlights the antagonistic nature of relations between females of different groups.

The intensity of intergroup battles varies from events in which just one or a few members of each group exchange vocal threats (aggressive growls) to events in which a majority of the adult females in each group are involved either directly in close-range fighting (threats and grappling combat) or indirectly by watching the unfolding confrontation (often vocalizing with chirps). The most intensely aggressive intergroup encounters seem to occur when most members of both groups are nearby at the time that the initial intergroup threats are exchanged; in this situation, other group members are best positioned to detect and rally around the animals who first exchange threats. The most intense intergroup encounters I have observed lasted as long as an hour, and grappling females drew blood. After one particular battle between two of our study groups, an adult female lay still, uncharacteristically low in the trees, in apparent shock for 40 minutes, her arms and tail covered with spots of blood apparently from multiple small puncture wounds suffered in the previous 45 minute aggressive encounter. By contrast, in 21 years I have never observed aggression between females within the same group that lasted so long, or resulted in physical injury this extreme, even though within-group conflicts occur at higher rates than those between groups. Across the 81 group-months in which observations of three study groups occurred on a regular (and usually daily) basis, the average rate of aggressive intergroup encounters was 0.5 per day.

Hostility between groups appears to be related to resource defense in a general way. Neighboring groups are more likely to interact aggressively at a shared territorial boundary when there is an attractive food source there that brings them together, and encourages trespassing. At the level of behavioral decision-making however, it seems clear that the convention of long-established boundaries is key. Even when there is no especially attractive food source present, interlopers caught on the wrong side of the boundary are chased back, and rarely put up any resistance, even when their group is bigger. Blue monkeys have a diverse diet, and gather plant 
or invertebrate food from most of the trees they pass through. Antagonism between groups thus serves to defend both especially rich food sources, and more general supplying areas.

Aggressive intergroup encounters demonstrate the dichotomy between ingroup and out-group relations in another way. The immediate aftermath of significant intergroup fights in Kakamega is characterized by a frenzy of grooming: females groom one another and their adult male (see also Payne et al., in press; Cheney, 1992 for similar observations on samango monkeys, C. mitis erythrarchus, and vervet monkeys, C. aethiops respectively). Typically, clumps of 3-4 animals are engaged in simultaneous grooming, and multiple clumps are just a few steps from each other in one tree crown, so that rapidly shifting partnerships are common. Although I have not been able to collect data systematically to evaluate the partner choices, it seems that most individuals hurry to groom with a variety of partners in a short time; this behavior contrasts with grooming that occurs in other contexts. The frenzy of grooming after intergroup battles gives the impression of being a display of 'us-versus-them' solidarity. In fact, it is during these moments of postaggression grooming that one gets the strongest impression that blue monkeys at Kakamega live in a group, since the individuals are extraordinarily cohesive. Under other circumstances, group members are often highly dispersed, with animals on the edges of the group separated by hundreds of meters, where they are out of sight of one another, and even out of earshot of quieter intragroup calls (grunts, trills). Blue monkey females spend most of their time $(40-70 \%)$ in trees containing no other monkeys. The contrast of this more usual situation with the post-encounter grooming activity is obvious, and suggests that cooperation in intergroup conflicts is an important aspect of the friendships that blue monkey females form with their groupmates.

Other studies of the intergroup relations of blue monkeys have come to conclusions that differed in some ways from the scenario described above, although they do not challenge the overall view that female friendship is confined to groupmates. In another high-density population in Cape Vidal (South Africa), Lawes \& Henzi (1995) noted that neighboring groups, who had fairly high degrees of range overlap, showed no aggression at all on more than half of the occasions when they were in close proximity. Furthermore, there was no clear relationship between the location of aggressive intergroup encounters and particular food resources (measured in several ways), and 
about half of the aggressive encounters observed did not occur when animals were feeding, or even near a feeding tree. These authors rejected the notion that blue monkeys are always territorial, although their data do not challenge the observation that relations between females of different groups do not involve overt affiliation, and do include antagonism. Furthermore, in a later study of the same population, Payne et al. (in press) found intergroup aggression more marked than the earlier report (indeed, it was 2-5 times more frequent than at Kakamega), and appear to accept more readily the idea that intergroup hostility is related to resource defense. This study also matches the observations from Kakamega that adult females were more likely than adult males to be involved in aggressive intergroup encounters, and that grooming (among females, and by females of the male) occurs at an elevated level shortly after encounters.

Another study that challenged the idea that blue monkeys are territorial focused on a low-density population in Ngogo/Kibale Forest (Uganda; Butynski, 1990). In a period of several years, Butynski never saw two groups less than $500 \mathrm{~m}$ apart, and never observed intergroup aggression. There was almost no range overlap between neighboring groups, which was attributed to the population being below carrying capacity, thus leaving considerable tracts of suitable but unused habitat between the home ranges of neighboring groups. Again, however, these results do not challenge the observation that female blue monkeys are antagonistic toward strangers. In this case, the opportunity to exhibit such antagonism just never occurred.

In sum, in the context of an entire population, friendships among adult female blue monkey groupmates appear to be related to intergroup competition, at least in populations whose densities are high enough to make such competition important. This qualification is perhaps important, since in lower-density populations, intergroup contests occur rarely if at all (Rudran, 1978; Butynski, 1990). It is not clear, however, that intergroup antagonism is irrelevant in the low density populations: the potential for aggression may lead to intergroup avoidance that is more successful (leading to fewer intergroup encounters) when groups are packed less densely. Indeed, in the population of intermediate density at Kanyawara/Kibale, Rudran (1978) and Struhsaker \& Leland (1979) characterize blue monkey groups as antagonistic and territorial, even though actual encounters were rarely observed.

However universally important intergroup competition is in blue monkeys, though, there may also be other advantages of living near female 
friends. Protection against predators through shared vigilance, improved detection of danger, and dilution, seems an obvious benefit of living in groups for these females, as well as many other primates (Hill \& Lee, 1998). Female groupmates also form coalitions to protect one another when adult males attack them, which occurs both in the context of actual or potential infanticide (i.e. the victim has a young infant; Butynski, 1982; Macleod, 2000) and at other times as well (e.g. while feeding, or when a male gets fed up with an estrous female's persistent attention; pers. obs.). However, it is during intergroup encounters that the banding together of the group's females is most frequent and most conspicuous, both in terms of their joint aggression against neighboring females, and in terms of the post-encounter grooming frenzies that appear to reaffirm their unity as a group. Grooming frenzies do not occur after attacks by predators or aggressive males. Attacks by predators and aggressive males also occur far less frequently at Kakamega than do intergroup encounters.

\section{Friendships within the group}

The within-group relationships of female non-vervet guenons, including blue monkeys, have been interpreted as egalitarian, with little differentiation among them in terms of affiliation and agonism (Sterck et al., 1997; Isbell \& Pruetz, 1998). For the Kakamega blue monkeys, this is an inaccurate description of within-group social organization: not all pairs of females have equivalent relationships. However, understanding the pattern of differentiation is not easy because the animals are so often alone, and social interaction is uncommon. Adult and subadult females spend an average of $<5 \%$ of their (day)time in overtly social activity such as grooming or sitting-incontact with one another. Of these, grooming is far more common. Sitting in close proximity $(\leqslant 1 \mathrm{~m})$ to other females, without any exchange of signals, is a possibly social activity that occupies just another $3 \%$ of daylight hours for the average female. Blue monkey females aren't forced to socialize rarely because of time constraints: the average female spends $30 \%$ of her daylight hours resting, time she might instead devote to social interaction. Females thus apparently choose to interact infrequently, and initial impressions, even those derived from months of study, suggest that social bonds are simply weak in general, and that group-wide patterns of agonistic relations are non-existent (Cords, 1987b). These impressions contrast with those 
quickly gained in the study of some other cercopithecine monkeys, in which friendly interaction occurs more frequently (see Dunbar, 1991 for some comparable figures on grooming times).

Long-term monitoring and focal animal data on blue monkeys in Kakamega have challenged this oversimplification. First, adult females are not equally friendly with members of all age-sex classes in their groups. They spend more time grooming with and being in proximity to other adult females than would be expected by chance (Cords, 2000). This is evidence, in the context of the entire group membership, for special relationships among adult females, who evidently prefer each other for these forms of interaction.

Second, there is substantial variation in the amount of time that each female devotes to grooming with her adult female partners (Fig. 1). Typically, the time spent grooming the favorite partner was at least 10 times greater than the time spent grooming the least favorite partner, and these figures exclude females who were not partners at all. The average female in the sample

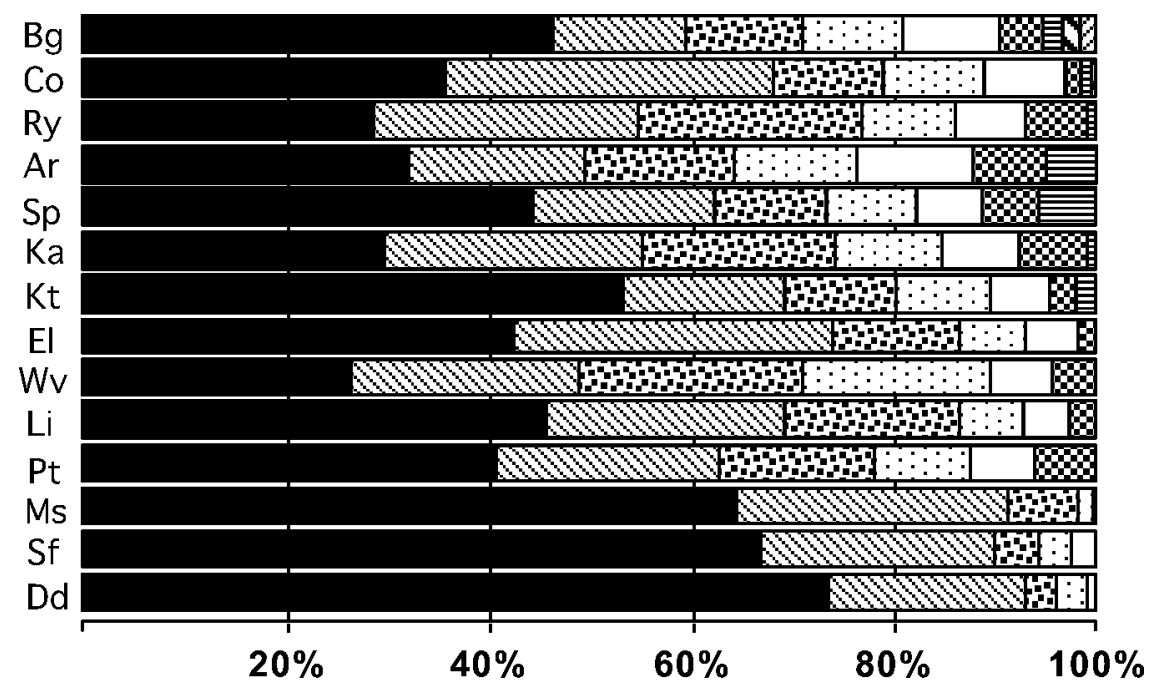

Percentage of grooming time

Fig. 1. Amount of time spent grooming with different adult female partners. Each bar represents the total grooming time (whether as groomer or recipient) of one adult female subject (initials given left of bar) with other adult female partners. The segments within each bar represent the proportion of grooming time spent with particular partners, arranged from left to right in order of descending importance. 
groomed with only 7 of the 14 partners available (Cords, 2000). A similar picture of differentiated grooming relationships emerges from non-focal data on the number of grooming interactions, collected from the same study group 5-10 years earlier: a few dyads groomed much more frequently than the majority of them (Rowell et al., 1991). Data on proximity partners indicate even greater differentials across dyads than grooming. Many females were in proximity (within $1 \mathrm{~m}$ ) to their most favored partner 100 times longer than with their least favored partner. Females spent time in close proximity with only 10 of 14 available partners (Cords, 2000).

In several other cercopithecines, the differentiation of social relationships among the females of a group can be related to rank, kinship, or both. A popular idea, stemming from Seyfarth's (1977) model explaining the distribution of grooming in baboons, is that grooming serves the purpose of cultivating beneficial alliances with powerful groupmates. Such alliances may benefit contestants in direct interference competition.

The feeding ecology of blue monkeys makes this idea seem applicable to them, at least in principle. Blue monkey diets usually include a large proportion of fruit (55\% of annual feeding records in Kakamega, Cords, 1987a, and 22-60\% of feeding records at other sites, Lawes, 1991) which appears to be a preferred food item. In Kakamega, fruit is harvested from trees that are not big enough to accommodate all group members, setting the stage for competitive interactions. Also, individual feeding bouts are long enough to be interrupted profitably, in that an interrupting individual is likely to have considerable time to feed at a site that s/he usurps (Isbell et al., 1998): at Kakamega, the median feeding bout length for fruit was 4.0 minutes in a sample of 68 such bouts from 15 adult females sampled for 5 hours each in 1992 (a bout was a continuous period of feeding in a single tree interrupted by other activities in the same tree for no more than $60 \mathrm{sec}$ at a time). $93 \%$ of agonism observed in focal samples of adult females occurred in the context of feeding, even though feeding accounts for only $54 \%$ of an average female's time budget (Cords, 2000). Furthermore, agonism was especially likely when the monkeys fed on fruit, and less likely than expected when they fed on leaves or invertebrates (other major components of the diet; Cords, 2000).

Overall, however, agonism in blue monkeys occurs rarely. An average female had an agonistic interaction only once in every 2.2 hours (with all potential opponents combined), and about $60 \%$ of these interactions 
were simple approach-retreat interactions with no signals of aggression exchanged (Cords, 2000). This rate is about 5 to $50 \%$ of those reported for other wild cercopithecines (Cords, 2000). The low rate alone might cast doubt on the importance of within-group interference competition, but actual contests may be rare if potential contestants adjust their behavior to avoid confrontation; in this case, one could not argue that interference competition is unimportant, and one would expect to see a relationship between prevailing in agonistic exchanges and some fitness-related variable.

Agonistic relations within the group could be arranged so that the females were ordered into a significantly linear dominance hierarchy (Cords, 2000; Fig. 2), even though direct observations of agonistic interactions in many dyads are missing because of the low interaction rates. Reversals, or interactions in which the winner-loser outcome went against the prevailing direction, were very rare (contra the claim of Isbell \& Pruetz, 1998, who referred to data from Rowell et al., 1991 that included juvenile females also).

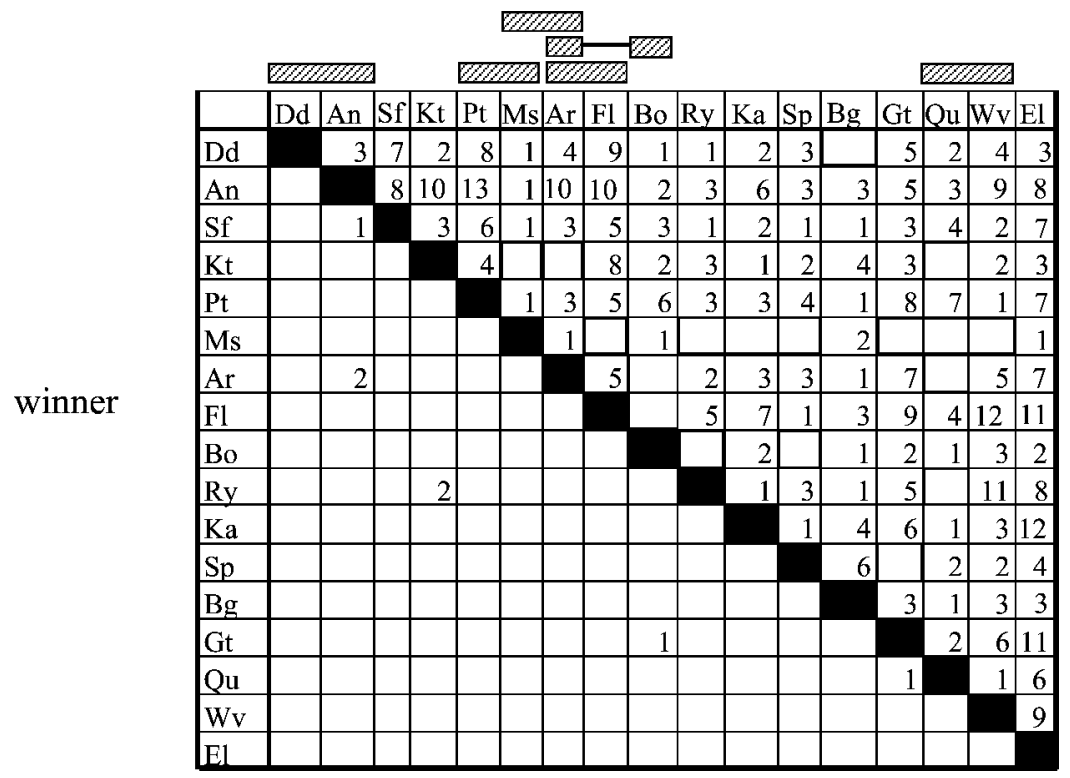

Fig. 2. Dominance hierarchy for adult females in the Tw group, 1996-1999. Row individuals prevailed against column individuals. Note similarity in rank order with data from 1992-1995 (Cords, 2000, Fig. 17.2). Hatched boxes at the top of the figure indicate all known motheroffspring pairs: mothers ranked higher than their offspring except for $\mathrm{Pt}$ and $\mathrm{Qu}$, who ranked higher than their mothers (Ms and Wv respectively). Linearity was assessed with the MatMan program (deVries, 1998). 
Furthermore, there was high consistency of individual rank positions: in the eight years (1993-2000) for which we have detailed records, all adult and sub-adult females but one have kept the same rank (see also Cords, 2000).

What determines a female's position in the hierarchy is not completely clear. Rank does not seem to be correlated with age, or with body size (Cords, 2000). There is some indication of maternal rank inheritance, in that juveniles interacting with third parties usually take the same relative position as their mothers do with the same opponent (Cords, 2000). Among the adult females, we know of a few sets of mother-daughter pairs, and daughters rank adjacently to mothers, whether just above or just below (Fig. 2).

In many cercopithecines, and especially those with maternal rank inheritance, coalitions are thought to be critical determinants of an adult female's rank position (Chapais, 1992). In the Kakamega blue monkeys, however, coalitions were exceedingly rare. Only one polyadic aggressive interaction (a mother defending her son against another adult female) was observed in 240 hours of focal animal sampling of adult females, and this represented only $2 \%$ of all aggressive interactions that occurred. This sample of coalitions was obviously too small to relate their patterning to other dimensions of social relationships. Blue monkeys also seem to lack specialized signals for recruiting coalition partners, while such signals are found in other species that regularly form coalitions (de Waal \& Harcourt, 1992); this fact also suggests that receiving coalitionary support is not very important for blue monkey adult females.

Another difference from many other cercopithecines is that rank position seems to have no obvious consequences for reproductive success in blue monkey females (Cords, 2000). In looking for such consequences, I focused initially on feeding behavior, because nearly all agonism took place in this context. However, females of different ranks did not differ systematically in the total amount of time they devoted to feeding, the time devoted to major dietary constituents (such as fruit, invertebrates or leaves), the time they spent on foods that were classified as dispersed $v s$ clumped, the time spent feeding in trees of different size, or trees occupied by different numbers of groupmates, or trees that differed in how 'full' they were (Cords, 2000). I also looked for rank effects in the ingestion rate of fruits since this was the food item for which a disproportionate number of contests occurred; for four important fruit species, however, there were no rank differences in bite rates (Cords, 2000). 
In case these analyses were too crude (perhaps I was missing a subtle aspect of food quality, for example), I then examined directly how rank relates to reproductive output. I included in this analysis only adult females whose reproductive history was known for at least 6 years (twice the usual interbirth interval in this population), and for whom that history began with the very first birth (to avoid problems with a reproductive slowdown in old age). This data set includes 5 more years of reproductive records, and 4 more females, than the one I reported previously (Cords, 2000); however, its conclusions are the same, in that there was no relationship between birth rate and a female's rank (Fig. 3; this conclusion held even if the analysis was limited to females with 9 years of reproductive records, which was the median number in the sample). This result is consistent with the lack of rank effects related to feeding (since good nutrition underlies successful reproduction), and also seems to rule out rank-related effects of stress on reproductive suppression.

Given that blue monkeys hardly ever form coalitions, and their access to food is evidently not influenced by rank, it is perhaps not surprising that rank was unrelated to the distribution of grooming (Cords, 2000). Neither the number of grooming partners, nor the total amount of grooming given to (or received from) all partners together, was related to rank. Within individual dyads, the partner that groomed most was not consistently the lower (or

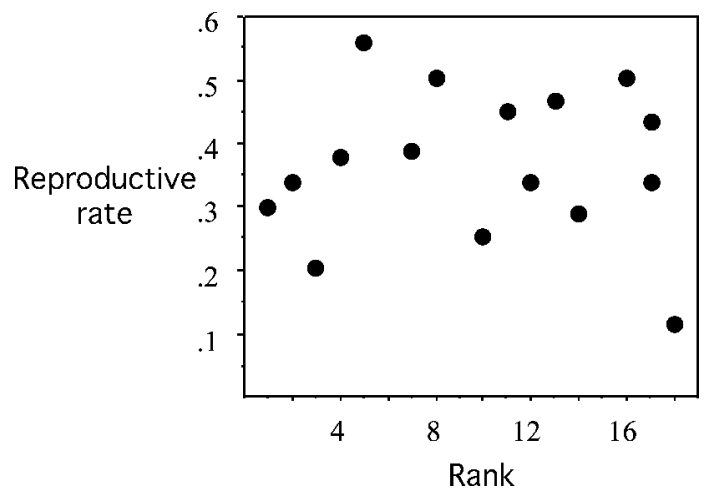

Fig. 3. Reproductive rate as a function of rank among adult females of the Tw group. Reproductive rate is the number of infants born that survived at least 12 months (and hence could be reliably detected by intermittent monitoring) per year of reproductive monitoring. Each female is represented by 5-19 years of reproductive records (median $=9 \mathrm{yrs}$ ), beginning at the time of birth of her first offspring. Reproductive data come from the period 1979-2001.

Agonistic rank data come from records in 1996-1999 (see Fig. 2). 
higher) ranking individual. Indeed, the amount of grooming that went up the hierarchy (averaging 46\% across all grooming dyads) was almost equal to the amount of grooming that went down the hierarchy. These observations do not support Seyfarth's model of grooming for the purpose of cultivating strategic alliances based on power differentials.

In 1999, Henzi \& Barrett proposed a different model to describe the grooming relationships of female primates, which moves away from the underlying assumption that grooming occurs to cultivate the favor of powerful coalition partners. While grooming may be traded for some kind of benefit dispensed by higher-ranking partners (perhaps simple tolerance, as an alternative to agonistic support), they also suggest that grooming may be a valuable commodity for trading in and of itself. One of their predictions is that when dominance gradients are shallow, and effective power differentials are weak — conditions which seem to apply to the Kakamega blue monkeys - grooming given is most likely to be traded for grooming received. In this case, one would expect a high degree of reciprocity in grooming interactions.

We have two small sets of data from our population that include precisely timed grooming bouts, and we found that there was indeed a significant correlation between the amounts of grooming given by each of the partners in a single two-way bout (Rowell et al., 1991). This symmetry within single grooming bouts, and the behavior involved in negotiating that symmetry (in the form of grooming solicitations, refusals to groom, counter-refusals, and apparent capitulations) are conspicuous features of grooming in blue monkey females. Unfortunately, the data set is too small to test some of the other predictions that Henzi \& Barrett have proposed, but the model is at least consistent with what we know for this species, and its premises seem much more reasonable.

Only one other study has addressed the nature of social relationships among individually recognized adult female $C$. mitis in the wild (Payne et al., in prep.). Similar to the blue monkeys at Kakamega, samango females at Cape Vidal (South Africa) showed both affiliative and agonistic relationships that were differentiated, including a significantly linear dominance hierarchy which was detectable even though behavioral sampling was of more limited duration, and the rate of agonistic encounters was $12 \%$ of that observed in Kakamega. As in Kakamega, feeding was the most frequently identified context for aggressive interaction (see also Rudran, 1978 for similar data 
from Kibale Forest, Uganda), and aggressive competition was disproportionately related to fruit-feeding. Rank position was not obviously related to fitness-related aspects of feeding behavior. No coalitions were observed. The amount of grooming given $v s$ the amount received was not related to the relative ranks of the grooming partners in a regular way, and reciprocal grooming was time-matched within bouts. In general, then, the nature of within-group relations among samangos and among blue monkeys in these two populations is very similar.

\section{Discussion: data and theory}

\section{Connections between within-group and between-group social relations}

Blue monkeys present a useful system in which to study empirically the influence of between-group competition on within-group social relations. Because between-group relations are evidently variable in this species, a comparison of multiple populations could reveal how the intensity of intergroup contest competition relates to the expression of affiliation and agonism within the group (e.g. Cheney, 1992). Such a comparison assumes that the expression of within-group relationships responds flexibly to varying environments, and there is evidence for such flexibility in other primate species (Barton et al., 1993; Koenig et al., 1998; Hill, 1999). To date, however, only two blue monkey populations can provide data on both between-group and within-group social relations, even if they fail to exemplify an ideal level of quantitation (Janson \& van Schaik, 1988). Between-group contests are frequent and conspicuous in Cape Vidal and Kakamega, and while the two sites thus do not provide contrasting regimes of between-group competition, it is at least encouraging that within-group relations are similar as well.

Nevertheless, there are certain characteristics of blue monkey social organization that do not seem to fit together in the way that theoretical typologies predict. Sterck et al. (1997) classified guenons (other than vervets) as resident-egalitarian species, in which females are philopatric, and dominance hierarchies are either absent or 'fuzzy' and non-linear. This social system was predicted to occur when between-group competition was strong and within-group competition was weak. The Kakamega and Cape Vidal data contradict the 'egalitarian' dimensions of this characterization. These data suggest that blue monkeys might fit better as a 'resident-nepotistic-tolerant' 
species, in which philopatric females show within-group competition (leading to clear hierarchical relationships) that is somewhat (but not completely) tempered by the strong between-group competition. The Kakamega data suggest maternal rank inheritance. However, both the rarity of coalition formation, and the fact that higher dominance rank seems to offer no competitive advantage, are problematical, for they undermine the premise of strong within-group contest competition; it is the strength of this kind of competition, according to the theory, that switches egalitarian agonistic relationships to nepotistic-tolerant ones.

A more fine grained comparison of the Kakamega and Cape Vidal study sites may reveal another way in which between-group relations influence friendships within the group. Coming from the perspective of biological markets, where the behavior of individuals is contingent on what others are doing, Payne et al. (in prep.) suggest that differential participation in between-group contests influences differentiation of grooming relations within the group. In particular, in a species like blue monkeys where power differentials between individuals are weak and don't influence reproductive success, grooming may be most important as a way of rewarding (or encouraging) a groupmate (high-ranking females at Cape Vidal) who is more active than the groomer in intergroup conflicts. While this is an interesting idea that deserves further attention, data from Kakamega cannot address it because thorough monitoring of participation in intergroup conflicts has not been possible. Payne's data are also not entirely convincing, since both the highest and lowest ranking females of their group received more grooming than they gave, although it was only the highest ranking females that participated more than expected in intergroup aggression. If this hypothesis is supported by future investigation, however, it may provide an explanation for Cheney's (1992) findings that between-group aggressive competition is not associated with how evenly females distribute their grooming activity with their groupmates.

\section{Relations within the group: what dominance hierarchies are about}

There seems to be little doubt that blue monkeys are not exactly the egalitarian animals that many have assumed. Although rare, their agonistic relations can be arranged in recognizable and stable linear hierarchies with few reversals, even if the power differentials from one rank to the next are 
small. What remains puzzling, however, is why the hierarchical relationships exist. A dyadic dominance relationship can be viewed as peace agreement that makes it possible to avoid risky, escalated aggression (Bernstein, 1981). The ordering of dyadic dominance relationships in a hierarchy, however, suggests that some characteristic of individuals - usually assumed to be their relative power - influences their relative positions. In blue monkeys and samangos, however, there is no evidence that rank position correlates with the prerogatives of power, such as access to better food, or higher reproductive rate.

One possibility is that the prerogatives of power have not been adequately measured in the field. Although current data suggest that rank is unrelated to dietary variables and reproductive rate, neither Payne et al. (in prep.) nor I has presented data on the relationship between rank and longevity. In long-lived animals like primates, longevity is an important contributor to variation in lifetime reproductive success (Fedigan, 1986; Altmann et al., 1988; Cheney et al., 1988; Bercovitch \& Berard, 1993; Kuester et al., 1995; van Noordwijk \& van Schaik, 1999). In other primate species, it has been related to dominance rank through the mechanism of competition for safe positions in the group (e.g. Robinson, 1981; van Noordwijk \& van Schaik, 1987; Ron et al., 1996; Hall \& Fedigan, 1997). It is also a difficult parameter to measure.

Very limited relevant information is available from the Tw study group in Kakamega, in which 4 females of known age have disappeared, and presumably died of natural (although unknown) causes, during the 10 year period in which rank relations are known (another two females were killed by local people and are excluded from consideration here). Most females $(18 / 20)$ who live long enough to give birth for the first time survive at least a year after their first birth. Two females did not survive for a full year after their first birth, and they were both in the middle third of the adult female dominance hierarchy. A third female died in the 8th year after her first birth, whereas 13 of 16 females who could have been monitored into their 8th years survived. A fourth female died in the 10th year after her first birth, whereas 8 of 10 females who could have been monitored into their 10 th years survived. These latter two females, who thus also appeared to have died unusually early, were both in the bottom sixth of the hierarchy. These results are not inconsistent with the idea that higher-ranking females suffer lower mortality, but many more records will be needed to make a convincing case. 
The lack of correlation between rank and measures related to reproductive success may alternatively result from the fact that the benefits of rank emerge only during rare 'crunch' times, which were not included in the sample. In 21 years of study of this population, there have been no obvious periods of unusually high mortality, but it remains possible that they occasionally occur.

A third possibility is that the rewards of high rank do not accrue in the currency of reproductive success. The ecology and behavior of blue monkeys may be such that competition while feeding is of little significance in terms of differentiating nutrient intake and consequent reproduction among individuals. There may, however, be a psychological benefit of high rank if high-ranking females are less often frustrated in achieving their immediate goals (i.e. satisfying their hunger). Animals would be expected to avoid such frustration if they can.

\section{The difficulties of evaluating rare behavior}

It has become a custom among primatologists to measure affiliation by quantifying the time that animals spend grooming or in unusually close proximity. As I have pointed out before (Cords, 1997), these are practical measures because they reflect long lasting and frequent behavioral states, and while no one has studied explicitly what variation in grooming or proximity time means, there are some data from some species that validate their interpretation as indicating friendship from a functional perspective. When these behaviors are rare, however, as in the case of blue monkey females, their interpretation is even more problematical. It is hard to know whether a quantitative comparison is valid, because differences may be largely random, and magnified in apparent importance against a background of modest occurrence. Increasing sample size is not always possible, either for logistical reasons, or because a long sampling period forces an assessment of a relationship that is changing over the long period, and hence does not reflect any real state at one time.

When affiliation is rare, we might therefore consider measuring other features besides its quantity. Examples include the readiness of a partner to groom when requested, or the likelihood that a partner is distracted by others; these measures may assess the motivation of social partners to engage in friendly behavior. Cords \& Aureli (2000) have proposed several other measures of various relationship characteristics, such as the partner's 
value, and the security of the relationship. These measures would allow a more multi-dimensional assay of friendship, and would likely add to our understanding even in species where affiliative behavior occurs more often.

The difficulty of evaluating rare behavior comes up in another context relevant to blue monkey friendships. Coalitions that settle disputes within the group are one benefit of primate friendships that have attracted much attention. Indeed, there is evidence that some primates may cultivate friendships to increase their chances of receiving agonistic support when needed (Cords, 1997). Coalitions in within-group agonism appear to be very rare for blue monkey adult females. This result has been documented in two populations, and it is consistent with other evidence that within-group contest competition may not be very strong. On the other hand, limited evidence suggests that there may be maternal rank inheritance, which in other cercopithecine species is known to result from coalitions (Chapais, 1992). Even without this hint of rank inheritance, one might legitimately ask whether coalitions are really unimportant just because they are rare. Might the threat of a coalition with a friend deter harassment, and thus be reason enough to cultivate a friendship? It is not so easy to evaluate the 'threat of coalition formation' when coalitions are rare. While one might predict that individuals with more friends would be harassed less often than those with fewer friends, it would be hard to determine, without experimental manipulation, if the reduction reflects the fact that friends are likely to form coalitions, rather than the fact that friends are reluctant to harass each other.

There are other species or populations of female-bonded Old World monkeys in which coalitions aimed to settle within-group disputes are rare, occurring at low rates per hour, or, perhaps more relevant, at low rates relative to opportunity (i.e. relative to the rate of aggression). Ron et al. (1996), whose chacma baboons (Papio cynocephalus ursinus) appeared to compete for safe positions rather than food, suggested that coalitions were rare because the resource being contested could not be shared. However, male baboons form coalitions to gain access to an unsharable estrous female, presumably because there is at least the chance that the 'favor' might be repaid at some later time. In the Yakushima Island Japanese macaques (Macaca fuscata), a low rate of coalition formation was related to the fact that aggressive competition was neither frequent nor intense, so that the benefit to the recipient of the coalition would likely be small (Hill \& Okayasu, 1995), and possibly not sufficient to compensate the costs to the 
ally. This explanation for rare coalitions may also apply to moor macaques (M. maurus, Matsumura, 1998) and to blue monkeys. For the latter, it is noteworthy in this context that individuals supplanted from particular feeding sites usually seem to suffer little, re-entering the feeding tree and resuming their activity. For blue monkeys, a large interindividual spread also probably increases the cost of intervening in a dispute, since the intervening animal has to travel, thereby giving up her own spot. To fully understand this rare behavior, and to put it in perspective for evaluating friendships in all primates, more systematic data will be required on the costs and benefits of participating in coalitions.

\section{References}

Altmann, J., Hausfater, G. \& Altmann, S.A. (1988). Determinants of reproductive success in savannah baboons, Papio cynocephalus. - In: Reproductive success: studies of individual variation in contrasting breeding systems (T.H. Clutton-Brock, ed.). University of Chicago Press, Chicago, p. 403-418.

Barton, R.A., Byrne, R.W. \& Whiten, A. (1993). Ecology, feeding competition and social structure in baboons. - Behav. Ecol. Sociobiol. 38, p. 321-329.

Bercovitch, F. \& Berard, J. (1993). Life history costs and consequences of rapid reproductive maturation in female rhesus macaques. - Behav. Ecol. Sociobiol. 32, p. 103-109.

Bernstein, I.S. (1981). Dominance: the baby and the bathwater. - Behav. Brain Sci. 4, p. 419-457.

Brooks, T., Pimm, S.L. \& Oyugi, J.O. (1999). Time lag between deforestation and bird extinction in tropical forest fragments. - Cons. Biol. 13, p. 1140-1150.

Butynski, T.M. (1982). Harem-male replacement and infanticide in the blue monkey (Cercopithecus mitis stuhlmanni) in the Kibale Forest, Uganda. - Am. J. Primatol. 3, p. $1-22$.

- - (1990). Comparative ecology of blue monkeys (Cercopithecus mitis) in high- and lowdensity subpopulations. - Ecol. Monogr. 60, p. 1-26.

Chapais, B. (1992). The role of alliances in social inheritance of rank among female primates. — In: Coalitions and alliances in humans and other animals (A.H. Harcourt \& F.B.M. de Waal, eds). Oxford University Press, New York, p. 29-59.

Cheney, D.L. (1992). Intragroup cohesion and intergroup hostility: the relation between grooming distributions and intergroup competition among females primates. - Behav. Ecol. 3, p. 334-345.

— - Seyfarth, R.M., Andelman, S.J. \& Lee, P.C. (1988). Reproductive success in vervet monkeys. - In: Reproductive success: studies of individual variation in contrasting breeding systems (T.H. Clutton-Brock, ed.). University of Chicago Press, Chicago, p. 384-402.

Cords, M. (1987a). Mixed-species association of Cercopithecus monkeys in the Kakamega Forest, Kenya. — Univ. Calif. Pub. Zool. 117, p. 1-109. 
— - (1987b). Male-male competition in one-male groups. — In: Primate societies (B.B. Smuts, D.L. Cheney, R.M. Seyfarth, R.W. Wrangham \& T.T. Struhsaker, eds). University of Chicago Press, Chicago, p. 98-111.

— - (1997). Friendships, alliances, reciprocity and repair. — In: Machiavellian intelligence II (A. Whiten \& R. Byrne, eds). Cambridge University Press, Cambridge, p. 24-49.

— - (2000). Agonistic and affiliative relationships in a blue monkey group. — In: Old world monkeys (P.F. Whitehead \& C.J. Jolly, eds). Cambridge University Press, Cambridge, p. 453-479.

— — \& Aureli, F. (2000). Reconciliation and relationship quality. — In: Natural conflict resolution (F. Aureli \& F.B.M. de Waal, eds). University of California Press, Berkeley, p. $177-198$.

Dunbar, R.I.M. (1991). Functional significance of social grooming in primates. — Folia primatol. 57, p. 121-131.

Fairgrieve, C. (1995). Infanticide and infant eating in the blue monkey (Cercopithecus mitis stuhlmanni) in the Budongo Forest Reserve, Uganda. — Folia primatol. 64, p. 69-72.

Fashing, P.J. \& Cords, M. (2000). Diurnal primate densities and biomass in the Kakamega Forest: An evaluation of census methods and a comarison with other forests. - Am. J. Primatol. 50, p. 139-152.

Fedigan, L.M., Fedigan, L., Gouzoules, S., Gouzoules H. \& Koyama, N. (1986). Lifetime reproductive success in female Japanese macaques. - Folia primatol. 47, p. 143-157.

Hall, C.L. \& Fedigan, L.M. (1997). Spatial benefits afforded by high rank in white-fronted capuchins. - Anim. Behav. 53, p. 1069-1082.

Hemelrijk, C.K. \& Luteijn, M. (1998). Philopatry, male presence and grooming reciprocation among female primates: a comparative perspective. - Behav. Ecol. Sociobiol. 42, p. 207-215.

Henzi, S.P. \& Barrett, L. (1999). The value of grooming to female primates. - Primates 40, p. 47-60.

Hill, D.A. (1999). Effects of provisioning on the social behaviour of Japanese and rhesus macaques: implications for socioecology. — Primates 40, p. 187-198.

— — \& Okayasu, N. (1995). Absence of 'youngest ascendancy' in the dominance relations of sisters in wild Japanese macaques (Macaca fuscata yakui). - Behaviour 132, p. 367-379.

— — \& Lee, P.C. (1998). Predation risk as an influence on group size in cercopithecoid primates: implications for social structure. - J. Zool., Lond. 245, p. 447-456.

Isbell, L.A. (1991). Contest and scramble competition: patterns of female aggression and ranging behavior among primates. - Behav. Ecol. 2, p. 143-155.

— — \& Pruetz, J.D. (1998). Differences between vervets (Cercopithecus aethiops) and patas monkeys (Erythrocebus patas) in agonistic interactions between adult females. - Int. J. Primatol. 19, p. 837-855.

— _ , _ — \& Young, T.P. (1998). Movements of vervets (Cercopithecus aethiops) and patas monkeys (Erythrocebus patas) as estimators of food resource size, density and distribution. - Behav. Ecol. Sociobiol. 42, p. 123-133.

- — \& van Vuren, D. (1996). Differential costs of locational and social dispersal and their consequences for female group-living primates. - Behaviour 133, p. 1-36.

Janson, C.H. \& van Schaik, C.P. (1988). Recognizing the many faces of primate food competition: methods. - Behaviour 105, p. 165-186. 
Koenig, A., Beise, J., Chalise, M.K. \& Ganzhorn, J.U. (1998). When females should contest for food - testing hypotheses about resource density, distribution, size and quality with Hanuman langurs. - Behav. Ecol. Sociobiol. 42, p. 225-237.

Kuester, J., Paul, A. \& Arnemann, J. (1995). Age-related and individual differences of reproductive success in male and female barbary macaques (Macaca sylvanus). Primates 36, p. 461-476.

Lawes, M.J. (1991). Diet of samango monkeys (Cercopithecus mitis erythrarchus) in Cape Vidal dune forest, South Africa. - J. Zool., Lond. 224, p. 149-173.

— — \& Henzi, S.P. (1995). Inter-group encounters in blue monkeys: how territorial must a territorial species be? - Anim. Behav. 49, p. 240-243.

Macleod, M. (2000). The reproductive strategies of samango monkeys (Cercopithecus mitis erythrarchus). PhD thesis, School of Life Sciences, University of Surrey Roehampton.

Matsumura, S. (1998). Relaxed dominance relations among female moor macaques (Macaca maurus) in their natural habitat, south Sulawesi, Indonesia. - Folia primatol. 69, p. 346-356.

Matsumura, S. (1999). The evolution of 'egalitarian' and 'despotic' social systems among macaques. - Primates 40, p. 23-31.

van Noordwijk, M.A. \& van Schaik, C.P. (1987). Competition among female long-tailed macaques, Macaca fascicularis. — Anim. Behav. 35, p. 577-589.

_ _ \& _ _ (1999). The effects of dominance rank and group size on female lifetime reproductive success in wild long-tailed macaques, Macaca fascicularis. — Primates 40, p. 105-130.

Payne, H.F.P., Lawes, M.J. \& Henzi, S.P. (in press). Competition and the exchange of grooming among female samango monkeys (Cercopithecus mitis erythrarchus). Behaviour.

Robinson, J.G. (1981). Spatial structure in foraging groups of wedge-capped capuchin monkeys Cebus nigrivittatus. - Anim. Behav. 29, p. 1036-1056.

Ron, T., Henzi, S.P. \& Motro, U. (1996). Do female chacma baboons compete for a safe spatial position in a southern woodland habitat? - Behaviour 133, p. 475-490.

Rowell, T.E., Wilson, C. \& Cords, M. (1991). Reciprocity and partner preference in grooming of female blue monkeys. - Int. J. Primatol. 12, p. 319-336.

Rudran, R. (1978). Socioecology of the blue monkeys (Cercopithecus mitis stuhlmanni) of the Kibale Forest, Uganda. - Smith. Contrib. Zool. 249, p. 1-88.

van Schaik, C.P. (1989). The ecology of social relationships amongst female primates. - In: Comparative socioecology: The behavioral ecology of humans and other mammals (V. Standen \& R.A. Foley, eds). Blackwell Scientific Publications, Oxford, p. 195-218.

Seyfarth, R.M. (1977). A model of social grooming among adult female monkeys. - J. Theor. Biol. 65, p. 671-698.

Sterck, E.H.M., Watts, D.P. \& van Schaik, C.P. (1997). The evolution of female social relationships in nonhuman primates. - Behav. Ecol. Sociobiol. 41, p. 291-309.

Struhsaker, T.T. \& Leland, L. (1979). Socioecology of five sympatric monkey species in the Kibale Forest, Uganda. - Adv. Stud. Behav. 9, p. 159-228.

de Vries, H. (1998). Finding a dominance order most consistent with a linear hierarchy: a new procedure and review. - Anim. Behav. 55, p. 827-843.

de Waal, F.B.M. \& Harcourt, A.H. (1992). Coalitions and alliances: a history of ethological research. - In: Coalitions and alliances in humans and other animals (A.H. Harcourt \& F.B.M. de Waal, eds). Oxford University Press, New York, p. 1-19. 
Wrangham, R.W. (1980). An ecological model of female-bonded primate groups. - Behaviour 75 , p. 262-300. 